\title{
Investigation of mass and energy coupling between soot particles and gas species in modelling ethylene counterflow diffusion flames
}

\author{
Citation for published version (APA): \\ Zimmer, L., Pereira, F. M., van Oijen, J. A., \& de Goey, L. P. H. (2017). Investigation of mass and energy \\ coupling between soot particles and gas species in modelling ethylene counterflow diffusion flames. Combustion \\ Theory and Modelling, 21(2), 358-379. https://doi.org/10.1080/13647830.2016.1238512
}

DOI:

10.1080/13647830.2016.1238512

Document status and date:

Published: 01/02/2017

Document Version:

Typeset version in publisher's lay-out, without final page, issue and volume numbers

\section{Please check the document version of this publication:}

- A submitted manuscript is the version of the article upon submission and before peer-review. There can be important differences between the submitted version and the official published version of record. People interested in the research are advised to contact the author for the final version of the publication, or visit the DOI to the publisher's website.

- The final author version and the galley proof are versions of the publication after peer review.

- The final published version features the final layout of the paper including the volume, issue and page numbers.

Link to publication

\footnotetext{
General rights

- You may freely distribute the URL identifying the publication in the public portal. follow below link for the End User Agreement:

www.tue.nl/taverne

Take down policy

If you believe that this document breaches copyright please contact us at:

openaccess@tue.nl

providing details and we will investigate your claim.
}

Copyright and moral rights for the publications made accessible in the public portal are retained by the authors and/or other copyright owners and it is a condition of accessing publications that users recognise and abide by the legal requirements associated with these rights.

- Users may download and print one copy of any publication from the public portal for the purpose of private study or research.

- You may not further distribute the material or use it for any profit-making activity or commercial gain

If the publication is distributed under the terms of Article 25fa of the Dutch Copyright Act, indicated by the "Taverne" license above, please 


\title{
Investigation of mass and energy coupling between soot particles and gas species in modelling ethylene counterflow diffusion flames
}

\author{
Leonardo Zimmer, Fernando Marcelo Pereira, Jeroen Adrianus van Oijen \& \\ Laurentius Philippus Hendrika de Goey
}

To cite this article: Leonardo Zimmer, Fernando Marcelo Pereira, Jeroen Adrianus van Oijen \& Laurentius Philippus Hendrika de Goey (2016): Investigation of mass and energy coupling between soot particles and gas species in modelling ethylene counterflow diffusion flames, Combustion Theory and Modelling, DOI: 10.1080/13647830.2016.1238512

To link to this article: http://dx.doi.org/10.1080/13647830.2016.1238512

曲 Published online: 14 Oct 2016.

Submit your article to this journal $\pi$

Q View related articles ¿

View Crossmark data \lceil 


\title{
Investigation of mass and energy coupling between soot particles and gas species in modelling ethylene counterflow diffusion flames
}

\author{
Leonardo Zimmer ${ }^{\mathrm{a}}$, Fernando Marcelo Pereira ${ }^{\mathrm{a}}$, Jeroen Adrianus van Oijen ${ }^{\mathrm{b}}{ }^{\mathrm{b}}$ and \\ Laurentius Philippus Hendrika de Goey (ib ${ }^{b}$ \\ ${ }^{a}$ Department of Mechanical Engineering, Federal University of Rio Grande do Sul, Porto Alegre, \\ Brazil; ${ }^{b}$ Department of Mechanical Engineering, Eindhoven University of Technology, Eindhoven, \\ The Netherlands
}

(Received 16 February 2016; accepted 6 September 2016)

\begin{abstract}
A numerical model is developed aiming at investigating soot formation in ethylene counterflow diffusion flames. The mass and energy coupling between soot solid particles and gas-phase species is investigated in detail. A semi-empirical two-equation model is chosen for predicting soot mass fraction and number density. The model describes particle nucleation, surface growth, and oxidation. A detailed kinetic mechanism is considered for the gas phase and the effect of considering radiation heat losses is also evaluated. Simulations were done for a range of conditions that produce low-to-significant amounts of soot using three strategies: first by changing the strain rate imposed on the flow field, second, by changing the oxygen content in the oxidant stream, and third, by changing the pressure. Additionally, the effect of the transport model chosen was analysed. The results showed that, for the flames studied and within the limits of the present work, the soot and gas radiation terms are of primary importance for numerical simulations. Additionally, it was shown that the soot mass and thermodynamic properties coupling terms are, in general, a second-order effect, with an importance that increases as soot amount increases. As a general recommendation, the radiation terms have always to be considered, whereas full coupling has to be employed only when the soot mass fraction, $Y_{S}$, is equal to or larger than 0.008 . If a higher precision is required, with errors less than $1 \%$, full coupling should be taken into account for $Y_{S} \geq 0.002$. For lower soot amounts, the coupling through soot mass and thermodynamic properties may be neglected as a first approximation, but an error on the total mass conservation will be present. Additionally, discrepancies from considering different transport models (detailed or simplified) are larger than those found from not fully coupling the phases.
\end{abstract}

Keywords: combustion; soot formation; soot model; counterflow diffusion flame; mass and energy coupling

\section{Introduction}

Soot is commonly found in diffusion flames of hydrocarbon fuels. The presence of soot particles increases the radiant heat losses, decreases the flame temperature, and gives a characteristic yellowish luminosity to the flame. The increased radiant heat transfer is not desirable for devices such as gas turbines and diesel engines due to a decrease of the device performance, but may be of interest in industrial furnaces where high heat transfer rates

*Corresponding author. Email: leo.zimmer@mecanica.ufrgs.br 
are required. In the flares of petrochemical plants or off-shore platforms, the presence of soot influences the intensity of the radiant heat flux at ground level, which determines the minimum stack height to protect personnel and equipment. In all cases, emissions of soot particles to the atmosphere are limited by law due to environmental and health concerns. Therefore, the capability of predicting soot formation in flames is important for many applications.

In [1] the models for soot prediction are grouped in three categories: (i) empirical correlations, (ii) semi-empirical models, and (iii) models with detailed chemistry. In the first category, models rely on global rate equations for soot generation and destruction adjusted to reproduce experimental data in specific combustion devices. They are easy to implement and are computationally fast, but since they do not describe soot formation steps, their validity is restricted to the conditions and devices for which they were developed. In the second category, the models attempt to incorporate some fundamental steps of the soot formation process, i.e. precursor formation, soot inception, particle growth, coagulation, and oxidation. Two typical examples of this model are the one from Leung et al. [2] and the one from Fairweather et al. [3]. These models usually take acetylene-based nucleation, instead of the more complex Polycyclic Aromatic Hydrocarbons (PAHs)-based nucleation, since the later requires the use of large gas-phase reaction mechanisms. The soot-particle dynamics is usually simplified, with the soot particles following a mono-disperse distribution that is described by a two-equation model, one for soot mass fraction $Y_{S}$ and another for soot number density $N_{S}$. Usually the rate equations that describe the soot formation processes are still dependent on the experimental conditions used to fit the model, but they are not dependent on specific devices. These models have demonstrated good agreement with experiments on global soot characteristics, like soot volume fraction and soot number density, but they lack detailed soot properties such as aggregate structure and size distribution [4]. In the third category, the models are improved with detailed kinetic mechanisms that can track the evolution of PAHs and with detailed soot dynamics that take into account the soot particle size distribution. The detailed gas-phase kinetic mechanisms are required to model the formation and consumption of PAHs as well as their interaction with the particle surface. The nucleation process involves collisions of molecules of benzene $\left(\mathrm{C}_{6} \mathrm{H}_{6}\right)$ [5], naphthalene $\left(\mathrm{C}_{10} \mathrm{H}_{8}\right)$ [6], pyrene $\left(\mathrm{C}_{16} \mathrm{H}_{10}\right)$ [7-9], or multiple PAHs [10]. Similarly, different species may participate in the evolution of PAHs and the particle surface growth process. The particle dynamics are modelled by many approaches, including the sectional method $[11,12]$, the method of moments $[13,14]$, and stochastic methods $[15,16]$. Since models in this category are more fundamental, they are likely to work in different combustion situations. The drawback of this approach is the difficult implementation and high computational costs [17], and even for these accurate models it is necessary to include some tuning parameters [9].

Special attention must be paid to the consumption and formation of some gas-phase species during soot nucleation, growth, and oxidation, requiring additional reaction source terms to be included in the species mass conservation equations and correction of the mixture density. On the other hand, the presence of soot particles implies additional energy source terms in the energy equation. For example, the radiant heat loss from soot is a well-known effect that reduces the flame temperature [18-21], and soot particles release heat when oxidised. Some works neglect the mass and energy coupling between gas and solid phases, considering that the amount of soot within the flame is so small that it does not change the flame composition and enthalpy [22,23]. But most soot research includes mass and energy coupling terms [6,12,16,20,21,24-27], although the importance of this choice is not always clear and frequently the implementation of such coupling terms is not 
clearly described. Thus, when modelling soot formation in flames one has to decide how these interactions should be accounted for.

The interaction between soot and gas-phase species was investigated by the following authors: Kennedy et al. [28] studied the soot formation in a laminar coflow ethylene-air diffusion flame. They used a semi-empirical model based on acetylene as the soot precursor and considered the mass coupling between the phases. Additional terms for $\mathrm{C}_{2} \mathrm{H}_{2}, \mathrm{OH}$, and $\mathrm{CO}$ in the gas-phase chemistry were accounted for due to soot reactions. The coupling was evaluated by comparing the solution of the gas-phase chemistry only, without radiation, against the solution of gas and soot, with mass coupling and soot radiation (no gas radiation). The authors found that the inclusion of soot in a coupled manner has a significant impact on the structure of the flame, specially near the flame tip where the soot amount was substantial. However, they did not quantify such impact on the flame. Carbonell et al. [29] studied the soot formation in a laminar coflow methane-air diffusion flame. They chose the Leung model [2] for soot prediction based on acetylene as the soot precursor. The authors compared versions of flamelet approaches, which included or not the effect of soot on the gas-phase chemistry, against a fully coupled detailed solution. The decoupled flamelet model, E-EDFM, obtained by decoupling the soot mechanism from the gas-phase mechanism, over-predicted the maximum soot volume fraction, $f_{v \text {, } \max }$, by $27.65 \%$ when compared with the most detailed version. According to the authors this happened because there was an excess of $\mathrm{C}_{2} \mathrm{H}_{2}$ in the flame which increases soot nucleation and growth. They concluded that the coupling was important, but again they presented no quantification of the differences and they didn't explore their model in different conditions. Di Domenico et al. [27] proposed a new soot formation model, based on a sectional approach for the description of PAHs and a two-equation model for soot. The model was validated for diffusion and partially premixed flames in a coflow burner for methane, ethylene, and kerosene. They included mass coupling between the soot and the gas-phase and soot radiative heat loss only. For the partially premixed ethylene case, they found that profiles of acetylene and benzene were slightly changed when soot radiation was accounted for, despite the temperature variations. Wang et al. [10] developed a PAH-based soot model based on the method of moments to simulate soot formation in ethylene counterflow diffusion flames. The soot model included thirty-six nucleation reactions from eight PAH molecules, particle surface growth from a modified HACA growth mechanism, PAH condensation, and particleparticle coagulation. The consumption and formation of soot related gas-phase species was accounted for as source terms to update gas-phase species concentrations. Compared to a gas-phase only solution, they found that the coronene (pyrene) concentration was reduced by $30.5 \%(10 \%)$ when soot was accounted for in the model (with mass and radiation coupling terms). Nevertheless, they did not quantify the soot coupling impact on other flame scalars and did not explore their model in different conditions.

Then, the question that still remains is what the conditions are for which a full description of the gas- and solid-phase interactions is mandatory. In this paper the mass and energy coupling between the soot particles and the gas-phase species is investigated for ethylene counterflow flames using a semi-empirical model. The semi-empirical model is chosen since it combines important steps for soot formation, good predictability of global soot variables and low computational time, specially for practical combustion systems. In order to determine whether the coupling effect is important, the model is explored in conditions that produce low and high amounts of soot by changing the strain rate imposed on the flow field, by increasing the oxygen concentration of the oxidiser and by increasing the pressure. Adiabatic and non-adiabatic (with radiation losses) simulations are investigated. Additionally, the effect of simplified transport properties modelling is analysed. 


\section{Numerical model}

Combustion problems are modelled with a set of partial differential equations that describe the conservations of total mass, mass of species, momentum, and energy. For counterflow flames, a one-dimensional approximation can be employed. The derivation of this set of equations can be found in [30].

\subsection{Soot model}

The soot model used in this work is based on [2,21]. This model is a semi-empirical acetylene based model that describes soot particle nucleation, surface growth, and oxidation. Two additional equations are included in the system of conservation equations, one for soot mass fraction, $Y_{S}$, and another for soot number density, $N_{S}$ (in particles per kilogramme of mixture). These two equations written for a stagnation flow read

$$
\begin{gathered}
\frac{\partial\left(\rho Y_{S}\right)}{\partial t}+\frac{\partial\left(\rho u Y_{S}\right)}{\partial x}=-\frac{\partial\left(\rho V_{T} Y_{S}\right)}{\partial x}+\frac{\partial}{\partial x}\left(\rho D_{s} \frac{\partial Y_{S}}{\partial x}\right)+\dot{w}_{Y_{S}}^{\prime \prime}-\rho K Y_{S}, \\
\frac{\partial\left(\rho N_{S}\right)}{\partial t}+\frac{\partial\left(\rho u N_{S}\right)}{\partial x}=-\frac{\partial\left(\rho V_{T} N_{S}\right)}{\partial x}+\frac{\partial}{\partial x}\left(\rho D_{s} \frac{\partial N_{S}}{\partial x}\right)+\dot{w}_{N_{S}}^{\prime \prime \prime}-\rho K N_{S},
\end{gathered}
$$

where $\rho$ is the mixture density (in $\mathrm{kg} \cdot \mathrm{m}^{-3}$ ), $u$ is the fluid velocity (in $\mathrm{m} \cdot \mathrm{s}^{-1}$ ), $V_{T}$ is the thermophoretic velocity of the soot particles (in $\mathrm{m} \cdot \mathrm{s}^{-1}$ ), $D_{s}$ is the soot diffusion coefficient (in $\mathrm{m}^{2} \cdot \mathrm{s}^{-1}$ ), $\dot{w}_{Y_{S}}^{\prime \prime \prime}$ and $\dot{w}_{N_{S}}^{\prime \prime \prime}$ are the source terms of the soot mass fraction (in $\mathrm{kg} \cdot \mathrm{m}^{-3} \mathrm{~s}^{-1}$ ) and soot number density (in particles per $\mathrm{m}^{-3} \mathrm{~s}^{-1}$ ), respectively, and $K$ is the stretch rate (in s${ }^{-1}$ ). The stretch rate $K$ accounts for the deviations from the one-dimensional condition [30]. Many research works $[2,3,19,21,31]$ neglect the Brownian motion of soot particles since soot transport is usually dominated by convective and thermophoretic effects. A small soot diffusion term is retained in this work to enhance numerical stability. In the same manner as in [32], wherein a soot diffusivity of $1 \%$ of the average gas diffusivity is used, the value of $D_{s}$ is set to $1 \times 10^{-6}\left(\mathrm{in}^{2} \cdot \mathrm{s}^{-1}\right)$. The thermophoretic velocity of soot, $V_{T}$, is modelled as

$$
V_{T}=-0.50 \frac{\mu}{\rho} \frac{1}{T} \frac{\partial T}{\partial x},
$$

where $\mu$ is the mixture dynamic viscosity (in $\mathrm{kg} \cdot \mathrm{m}^{-1} \mathrm{~s}^{-1}$ ) and $T$ is the mixture temperature (in K).

The soot related reactions are presented in the Table 1. It is a simplified mechanism that neglects many phenomena involved in soot formation. The destruction of particles by

Table 1. Soot reactions.

\begin{tabular}{lcc}
\hline Nucleation & $\mathrm{C}_{2} \mathrm{H}_{2} \rightarrow 2 \mathrm{C}_{S}+\mathrm{H}_{2}$ & $R_{1}$ \\
Surface growth & $\mathrm{C}_{2} \mathrm{H}_{2}+n \mathrm{C}_{S} \rightarrow(n+2) \mathrm{C}_{S}+\mathrm{H}_{2}$ & $R_{2}$ \\
Oxidation by $\mathrm{O}_{2}$ & $\mathrm{C}_{S}+\frac{1}{2} \mathrm{O}_{2} \rightarrow \mathrm{CO}$ & $R_{3}$ \\
Oxidation by OH & $\mathrm{C}_{S}+\mathrm{OH} \rightarrow \mathrm{CO}+\mathrm{H}$ & $R_{4}$ \\
Oxidation by O & $\mathrm{C}_{S}+\mathrm{O} \rightarrow \mathrm{CO}$ & $R_{5}$ \\
\hline
\end{tabular}


coagulation was neglected as suggested in $[19,21,33]$. There is only one species responsible for soot nucleation and surface growth, neglecting the role of many PAHs. Also, the aerosol of particles is assumed to be mono-disperse. Nevertheless, this model is good enough for the purposes of the present work, i.e. to evaluate the importance of the coupling terms between the gas-phase and soot particles.

In this model the first reaction for soot formation is the nucleation of the first particle, which employs acetylene as a representative species of the soot precursors. The soot particle is represented as solid carbon, $\mathrm{C}_{S}$. The second reaction is the surface growth due to adsorption and reaction of $\mathrm{C}_{2} \mathrm{H}_{2}$ on the surface of the particle. The third, fourth, and fifth reactions model soot mass consumption by surface oxidation by $\mathrm{O}_{2}, \mathrm{OH}$, and $\mathrm{O}$, respectively.

The source terms for soot mass fraction, Equation (1), and soot number density, Equation (2), are

$$
\begin{gathered}
\dot{w}_{Y_{S}}^{\prime \prime \prime}=M_{S}\left(2 R_{1}+2 R_{2}-R_{3}-R_{4}-R_{5}\right), \\
\dot{w}_{N_{S}}^{\prime \prime \prime}=\frac{2}{C_{\min }} N_{A} R_{1},
\end{gathered}
$$

where $M_{S}=12.011$ (in $\mathrm{kg} \cdot \mathrm{kmol}^{-1}$ ) is the carbon molar mass, $C_{\min }=700$ is the average number of carbon atoms in the incipient soot particle, and $N_{A}=6.022 \times 10^{26}$ (in particles per kmol ${ }^{-1}$ ) is Avogadro's number. Equation (4) takes into account soot nucleation, surface growth, and oxidation by $\mathrm{O}_{2}, \mathrm{OH}$, and $\mathrm{O}$. Equation (5) takes into account the production of particles by soot nucleation only.

The nucleation rate $R_{1}$ (in $\mathrm{kmol} \cdot \mathrm{m}^{-3} \mathrm{~s}^{-1}$ ), and its rate constant $k_{1}$ are written as

$$
R_{1}=k_{1}(T)\left[\mathrm{C}_{2} \mathrm{H}_{2}\right], \quad k_{1}=1.0 \times 10^{3} \exp \left(\frac{-16,103}{T}\right)
$$

where $\left[\mathrm{C}_{2} \mathrm{H}_{2}\right]$ is the acetylene concentration (in $\mathrm{kmol} \cdot \mathrm{m}^{-3}$ ).

The surface growth rate, $R_{2}$ (in $\mathrm{kmol} \cdot \mathrm{m}^{-3} \mathrm{~s}^{-1}$ ), and its rate constant $k_{2}$ are written as

$$
R_{2}=k_{2}(T) f(S)\left[\mathrm{C}_{2} \mathrm{H}_{2}\right], \quad k_{2}=7.0 \times 10^{2} \exp \left(\frac{-10,064}{T}\right),
$$

where $f(S)$ is a function that expresses the dependence of the surface growth term on the specific soot surface area, $S$ (in $\mathrm{m}^{2} \cdot \mathrm{m}^{-3}$ ). In this model $f(S)=\sqrt{S}$ and $S=\pi d_{p}^{2}\left(\rho N_{S}\right)$. The soot particle diameter, $d_{p}$ (in $\mathrm{m}$ ), can be obtained as

$$
d_{p}=\left(\frac{6 Y_{S}}{\pi \rho_{C} N_{S}}\right)^{1 / 3}
$$

where $\rho_{C}=1900$ (in $\mathrm{kg} \cdot \mathrm{m}^{-3}$ ) is the soot density.

The oxidation by $\mathrm{O}_{2}$ is based on the Nagle-Strickland-Constable (NSC) model [34]. In this model, it is assumed that there are two types of sites, one more reactive (A) and another less reactive (B), on the carbon surface. The oxidation rate, $R_{3}\left(\right.$ in $\mathrm{kmol} \cdot \mathrm{m}^{-3} \mathrm{~s}^{-1}$ ), and its 
rate constant $k_{3}$ are written as

$$
R_{3}=k_{3} S, \quad k_{3}=\left(\frac{k_{\mathrm{A}} P_{\mathrm{O}_{2}}}{1+k_{\mathrm{Z}} P_{\mathrm{O}_{2}}}\right) x_{\mathrm{A}}+k_{\mathrm{B}} P_{\mathrm{O}_{2}}\left(1-x_{A}\right),
$$

where $P_{\mathrm{O}_{2}}$ is the partial pressure of $\mathrm{O}_{2}$ (in atm), and the intrinsic constant rates of the model, $k_{\mathrm{A}}, k_{\mathrm{Z}}, k_{\mathrm{B}}$, and $k_{\mathrm{T}}$, and the fraction of the surfaces $x_{\mathrm{A}}$ that is covered by the sites $\mathrm{A}$ are

$$
\begin{gathered}
k_{\mathrm{A}}=200 \exp (-15,098 / T), \\
k_{\mathrm{Z}}=21.3 \exp (2,063 / T), \\
k_{\mathrm{B}}=4.46 \times 10^{-2} \exp (-7,650 / T), \\
k_{\mathrm{T}}=1.51 \times 10^{6} \exp (-48,817 / T), \\
x_{\mathrm{A}}=\left(1+\frac{k_{\mathrm{T}}}{k_{\mathrm{B}} P_{\mathrm{O}_{2}}}\right)^{-1} .
\end{gathered}
$$

The oxidation rate by the $\mathrm{OH}$ radical $R_{4}\left(\mathrm{in} \mathrm{kmol} \cdot \mathrm{m}^{-3} \mathrm{~s}^{-1}\right.$ ) and its rate constant $k_{4}$, taken from [22], are written as

$$
R_{4}=k_{4} S, \quad k_{4}=1.044 \times 10^{-3} \varphi_{\mathrm{OH}} T^{-1 / 2} p_{\mathrm{OH}}
$$

where $\varphi_{\mathrm{OH}}$ is the collision efficiency for $\mathrm{OH}$ and $p_{\mathrm{OH}}$ is the $\mathrm{OH}$ partial pressure (in $\mathrm{Pa}$ ). The collision efficiency is assumed to be equal to 0.2 .

The oxidation rate $R_{5}$ by the $\mathrm{O}$ radical and its rate constant $k_{5}$, taken from [35], are written as

$$
R_{5}=k_{5} S, \quad k_{5}=1.094 \times 10^{-3} \varphi_{\mathrm{O}} T^{-1 / 2} p_{\mathrm{O}}
$$

where $\varphi_{\mathrm{O}}$ is the collision efficiency for $\mathrm{O}$ and $p_{\mathrm{O}}$ is the $\mathrm{O}$ partial pressure (in $\mathrm{Pa}$ ). The collision efficiency is also assumed to be equal to 0.2 .

The soot volume fraction, $f_{v}$, is found from the computed soot mass fraction as

$$
f_{v}=\frac{\rho Y_{S}}{\rho_{\mathrm{C}}} .
$$

The soot model described above is not valid for very large residence times, i.e. for extremely low strain rates. Since the model does not consider reversible reactions, it is not able to reach the equilibrium conditions and very large quantities of soot are predicted. This limitation was also pointed out in $[1,36]$. Eaves et al. [36] showed that, by considering the reversibility in modelling soot nucleation and condensation processes, the agreement of numerical studies with experimental data of ethylene laminar coflow flames improved. 


\subsection{Radiation model}

The radiant heat losses are modelled by using the grey-gas approximation, i.e. assuming no dependence on the wave number in the optically thin limit, i.e. the medium neither scatters nor absorbs radiation. Then, the heat source in the energy conservation equation due to gas and soot radiant heat losses $[27,29,37,38]$ is

$$
\begin{gathered}
q_{R}^{\prime \prime \prime}=q_{R, \mathrm{gas}}^{\prime \prime \prime}+q_{R, \mathrm{soot}}^{\prime \prime \prime}, \\
q_{R, \mathrm{gas}}^{\prime \prime \prime}=-4 \sigma \kappa\left(T^{4}-T_{\infty}^{4}\right), \\
q_{R, \mathrm{soot}}^{\prime \prime \prime}=-C f_{v} T^{5},
\end{gathered}
$$

where $T_{\infty}$ is the surrounding temperature, $\sigma$ is the Stefan-Boltzmann constant $(5.669 \times$ $10^{-8} \mathrm{~W} \cdot \mathrm{m}^{-2} \mathrm{~K}^{-4}$ ) and the constant $C=4.243 \times 10^{-4}$ (in W. $\mathrm{m}^{-3} \mathrm{~K}^{-5}$ ) is taken from [38]. $\kappa=\sum p_{i, \text { atm }} \kappa_{i}$ denotes the Planck mean absorption coefficient of the mixture (in $\mathrm{m}^{-1}$ ), and $p_{i \text {, atm }}$ and $\kappa_{i}$ are, respectively, the partial pressure (in atm) and the Planck mean absorption coefficient of species $i$ (in atm ${ }^{-1} \mathrm{~m}^{-1}$ ). The participant gas species are $\mathrm{H}_{2} \mathrm{O}, \mathrm{CO}_{2}, \mathrm{CO}$, and $\mathrm{CH}_{4}$. The Plank mean absorption coefficients for $\mathrm{H}_{2} \mathrm{O}$ and $\mathrm{CO}_{2}$ are given in [39] and for $\mathrm{CO}$ and $\mathrm{CH}_{4}$ are given in [40]. In Equation (20), it is considered that the absorption term is negligible when compared with the emission term. Since in our results there is no soot in low temperature regions, this approximation is accurate enough for the present study.

\subsection{Coupling of soot and gas-phase species}

The solid-phase is modelled as an additional species, the $(N+1) t h$ species in the mixture $\left(Y_{N+1}=Y_{S}\right)$. The interaction between the soot chemistry and the gas-phase chemistry was accounted for in the transport equations for the total mass, for the mass of species and for energy. This means that additional source terms for species related to soot formation and oxidation $\left(\mathrm{C}_{2} \mathrm{H}_{2}, \mathrm{H}_{2}, \mathrm{CO}, \mathrm{H}, \mathrm{O}_{2}, \mathrm{OH}\right.$, and $\left.\mathrm{O}\right)$ are added to the system of equations. Thus, the elements are conserved, the summation of species mass fractions is equal to one $\left(\sum_{i=1}^{N+1} Y_{i}=1\right)$ and the summation of species source terms (on a mass basis) is equal to zero $\left(\sum_{i=1}^{N+1} \dot{w}_{i}^{\prime \prime \prime}=0\right)$. To guarantee mass conservation, the correction of diffusion fluxes is applied to all species, including soot. Additional soot terms in the mixture enthalpy and heat capacity are added as $h=\sum_{i=1}^{N+1} Y_{i} h_{i}$ and $c_{p}=\sum_{i=1}^{N+1} Y_{i} c_{p_{i}}$. The thermodynamic properties for soot $\left(h_{i}\right.$ and $\left.c_{p_{i}}\right)$ are approximated using the properties of solid carbon (graphite) and the data are taken from the NIST-JANAF database [41]. For simplicity it is assumed that soot does not affect the mixture viscosity and thermal conductivity. An additional term in the energy flux, $j_{q}$ (in $\mathrm{kJ} \cdot \mathrm{m}^{-2} \mathrm{~s}^{-1}$ ), due to the soot thermophoretic diffusion flux, the $(N+1)$ th species, is added:

$$
j_{q}=-\lambda \nabla T+\sum_{i=1}^{N+1} h_{i} j_{i},
$$

where $\lambda$ is the thermal conductivity (in $\mathrm{kW} \cdot \mathrm{m}^{-1} \mathrm{~K}^{-1}$ ), $j_{i}$ is the species $i$ mass diffusion flux (in $\mathrm{kg} \cdot \mathrm{m}^{-2} \mathrm{~s}^{-1}$ ). The mixture density, $\rho$, is calculated as the density for multiphase flows 
according to [42]:

$$
\rho=f_{v} \rho_{\mathrm{C}}+\left(1-f_{v}\right) \rho_{\mathrm{gas}},
$$

where the density of the gas phase, $\rho_{\text {gas }}$, is calculated by the ideal-gas equation of state using the low-Mach-number approximation

$$
\rho_{\mathrm{gas}}=\frac{p M W_{\mathrm{gas}}}{R T}, \quad M W_{\mathrm{gas}}=\left(\sum_{i=1}^{N} \frac{Y_{i}^{*}}{M W_{i}}\right)^{-1},
$$

where $p=p_{\text {amb }}$ is the ambient pressure (in $\mathrm{Pa}$ ), $R$ is the universal gas constant $\left(8.3144 \mathrm{~J} \cdot \mathrm{mol}^{-1} \mathrm{~K}^{-1}\right), M W_{\text {gas }}$ is the molar mass of the gas phase only (in $\mathrm{kg} \cdot \mathrm{kmol}^{-1}$ ) and $M W_{i}$ is the species $i$ molar mass. To calculate $M W_{\text {gas }}$ it is necessary to rescale the species mass fraction according to $Y_{i}^{*}=Y_{i} /\left(1-Y_{S}\right)$.

\subsection{Numerical method}

The system of equations was solved with the code CHEM1D [43] for steady-state conditions. The chemical kinetic mechanism of Blanquart, Pepiot-Desjardins, and Pitsch [44] was used. This chemical mechanism, consisting of 148 species and 928 reactions, was developed for the high-temperature combustion over a wide range of pressures for hydrocarbon fuels ranging from methane to iso-octane. The diffusion coefficients were calculated through the mixture-average approach in which the diffusion velocity of each individual gas species is computed assuming Fick-like diffusion with correction of diffusion fluxes for all species. Viscosity was calculated through Wilke's approximation [45] and thermal conductivity was calculated through the combination-averaging approach of Mathur [46].

The fuel stream is pure ethylene and the oxidiser stream has the simplified composition of standard dry air $\left(Y_{\mathrm{O}_{2}}=0.233\right.$ and $\left.Y_{\mathrm{N}_{2}}=0.767\right)$. All cases converged using a convergence criterion of $1 \times 10^{-10}$. Adaptive mesh refinement was used according to the gradients of the following variables: temperature, density, heat release, $Y_{S}, N_{S}, Y_{\mathrm{C}_{2} \mathrm{H}_{2}}, Y_{\mathrm{O}}$, and $Y_{\mathrm{H}}$. The distance of both boundaries to the stagnation plane are set as $x_{\text {left }}=-2 \mathrm{~cm}$ and $x_{\text {right }}$ $=2 \mathrm{~cm}$, sufficiently large for all gradients near the boundaries to become zero, except for velocity, which follows a potential flow. It was found that the results for all variables analysed in the current work became grid independent for 400 points.

An assessment of the current model was done and the results of three non-adiabatic cases were compared with the experimental work of Hwang and Chung [47] and Vandsburger et al. [48], and the numerical work of Liu et al. [21]. The chemical kinetic mechanism used for this assessment was GRI v3.0 [49], the same as for the reference. The comparison with experiments was in good qualitative agreement and the differences observed in the numerical comparison are due to the different reacting flow codes that were used (the reference used the code described in [50]). Figure 1 shows the comparison of $f_{v}$ for three levels of oxygen concentration at the oxidant stream.

\section{Results and discussion}

The impact of the mass and energy coupling terms on the flame simulation are evaluated for ethylene/air counterflow flames in a variety of conditions. Results are presented in four parts. In the first part some basic aspects of the flame structure are presented for low and 




Figure 1. Comparison of $f_{v}$ results for three levels of oxygen molar fraction at the oxidiser stream, $X_{\mathrm{O}_{2}}$. Open symbols: Hwang and Chung [47]; closed symbols: Vandsburger et al. [48]; solid line: present simulation; and dash-dot line: reference simulation [21].

high values of strain rate. In the second part different radiation models are compared and discussed, highlighting the importance of this coupling term for soot predictions.

In the third part, additional coupling terms for mass and thermodynamic properties are explored in detailed in order to determine the conditions for which the fully coupled model is necessary. Numerical simulations were conducted for four different situations. Two simulations were adiabatic and two were non-adiabatic (i.e. with radiant heat losses, Equation 18). Within each heat loss condition two different cases were tested. In the first case, here called 'coupled', the gas-phase composition and thermodynamic properties are influenced by soot formation and oxidation, with the additional terms presented in Section 2.3. In the second case, here called 'non-coupled', the gas-phase composition and thermodynamic properties are not influenced by soot formation or oxidation (none of the additional terms presented in Section 2.3 is used), and the only coupling effect that is kept is the radiant heat loss from soot in the energy equation. Therefore, there is no conservation of mass or energy, and the mixture density is evaluated only by the gas phase.

In the last part, the effect of different transport models on the flame simulation is presented and compared with the effect of coupling terms.

\subsection{Flame structure}

The impact of flow field on the flame structure for two different values of strain rate, $a=$ $(\mathrm{d} u / \mathrm{d} x)_{x \rightarrow \infty}$, applied at the oxidiser side, is presented. One flame has $a=100 \mathrm{~s}^{-1}$, i.e. a small residence time that leads to a low $f_{v}$, and the other has $a=10 \mathrm{~s}^{-1}$, i.e. a long residence time that leads to a high $f_{v}$.

The flame structure for $a=100 \mathrm{~s}^{-1}$ for the adiabatic and coupled case is presented in Figure 2. Species related to soot production and oxidation and temperature profiles are presented in physical space. The gas stagnation plane is located at $x=0 \mathrm{~cm}$ and the reaction zone is located in the oxidiser side. Soot particles are present in the region where 


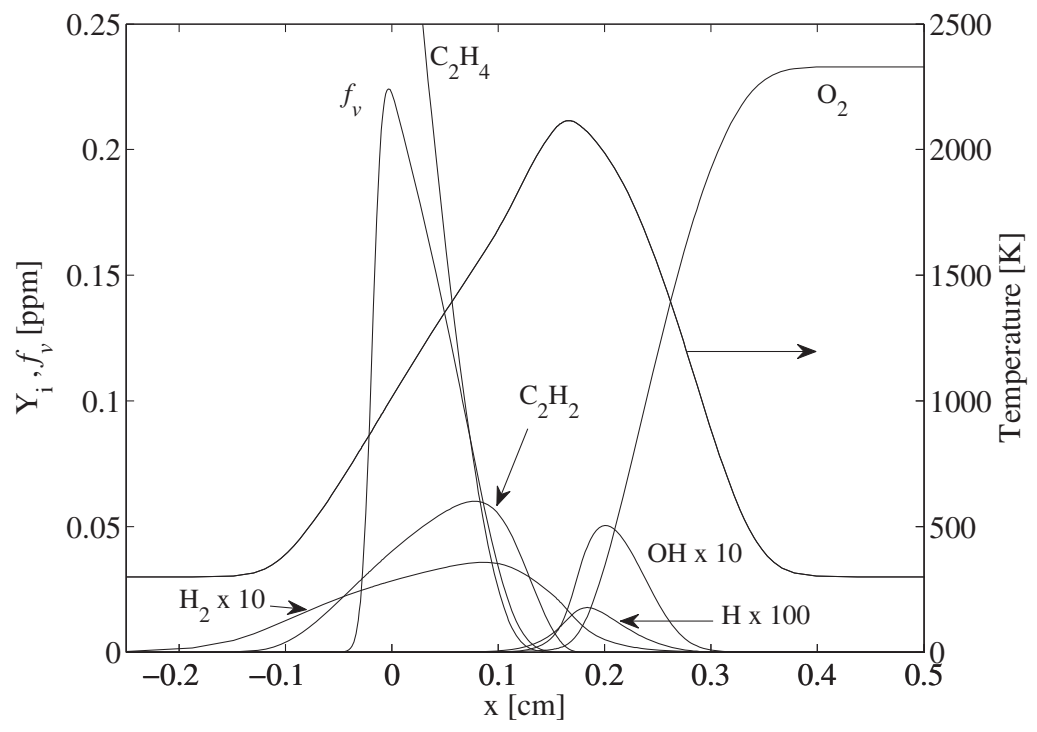

Figure 2. Flame structure for $a=100 \mathrm{~s}^{-1}$ for the coupled, adiabatic case.

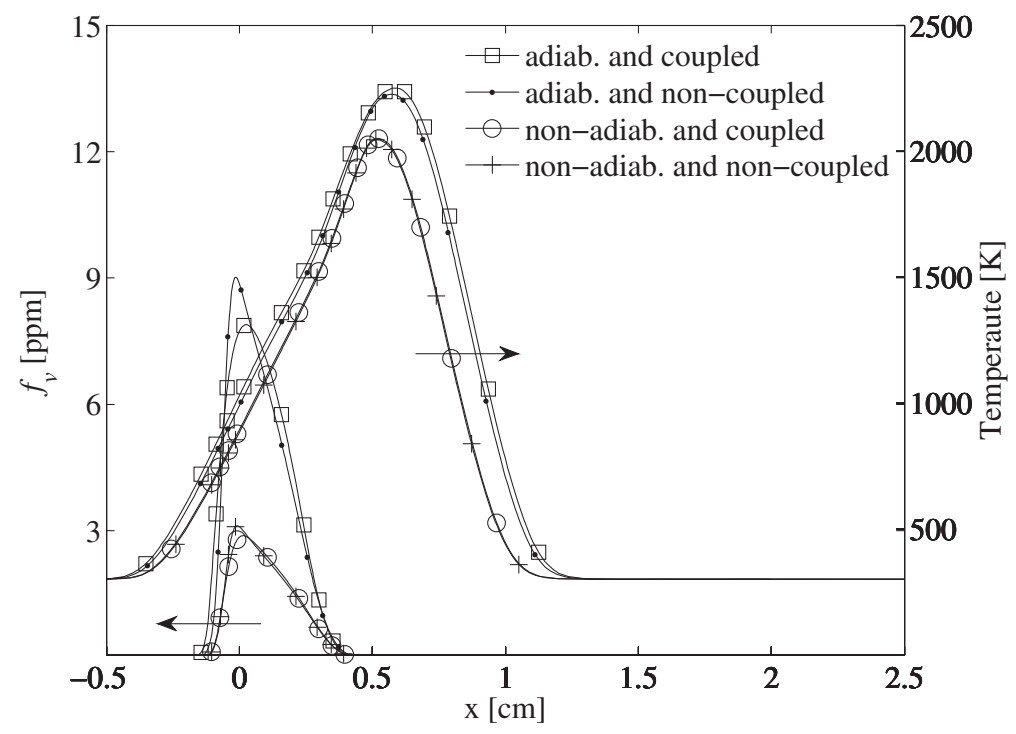

Figure 3. Profiles of $f_{v}$ and temperature for $a=10 \mathrm{~s}^{-1}$.

high temperatures and high acetylene concentrations are found. For this condition, the maximum $f_{v}$ is equal to $0.225 \mathrm{ppm}$ (corresponding to a maximum $Y_{S}$ of 0.0013 ).

As the residence time is increased, the flame thickness and the amount of soot produced are also increased. The $f_{v}$ and the temperature profiles for $a=10 \mathrm{~s}^{-1}$ for the four situations under investigation are plotted in Figure 3. In this figure it is possible to observe that the inclusion of the radiation model is important for the flame simulations, while the additional coupling terms have a lower impact. Qualitatively the profiles are similar for the four situations under investigation. The largest differences are usually found close 


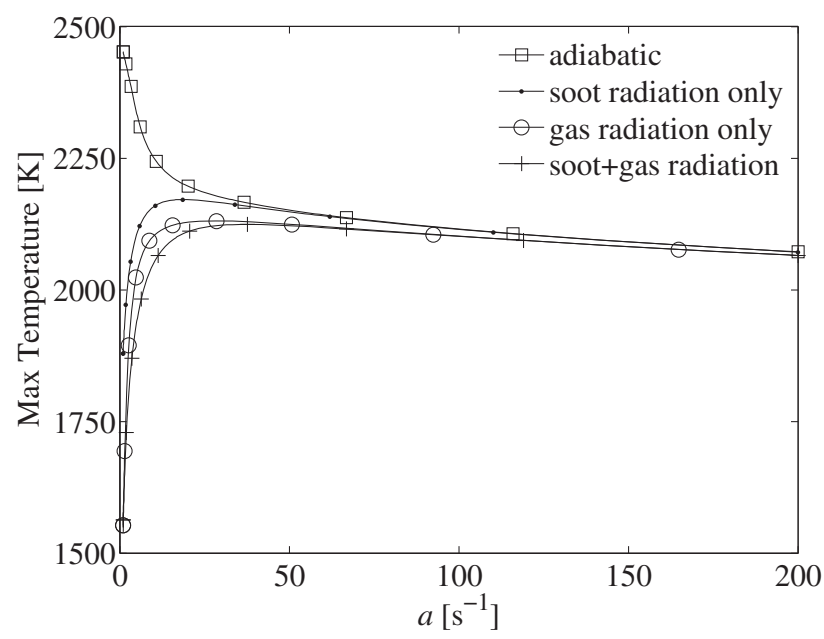

Figure 4. Comparison of maximum temperature for different radiative heat losses as a function of the strain rate $a$.

to the maximum value of each variable. Thus, in the discussions that follow, only the differences in the peak values of each variable of interest will be presented.

\subsection{Coupling through radiative heat losses}

In the previous section it was found that the coupling of radiative heat loss had a large impact on the flame structure. Therefore, in this section, the heat loss by soot and gas radiation is discussed in more detail. Numerical simulations were conducted for four different radiation models. One simulation was adiabatic, one with soot radiation only, another with gas radiation only, and the last with both soot and gas radiation (previously referred to as the non-adiabatic condition). All simulations were done using the coupled approach, with the terms presented in Section 2.3. To explore a large range of soot volume fractions, the strain rate $a$ is varied from 1 to $200 \mathrm{~s}^{-1}$.

Figure 4 presents the maximum temperature as a function of the strain rate $a$. As the residence time increases ( $a$ decreases) the effect of radiative heat loss becomes so significant that the flame is eventually extinguished. It is also possible to see that as the amount of soot increases (see Figure 5) the soot radiation becomes important and generates a decrease in the flame temperature similar to that observed for the gas-phase radiation model. An important aspect is that the soot radiation source term is concentrated in the region of high soot volume fraction (close to the stagnation plane). In this region the predicted temperature is lower for the model considering only soot radiation when compared with that considering only gas radiation. The opposite is observed for the maximum flame temperature as seen in Figure 4, since the gas radiation source term is important in a much wider region.

In Figure 5 it is possible to see that the maximum soot volume fraction is differently affected by each heat loss condition. The maximum values of $f_{v}$ are 5.74, 8.28, and $3.15 \mathrm{ppm}$, for the soot radiation only, gas radiation only, and the combined soot and gas radiation conditions, respectively. This is due to the fact that each condition distinctly affects the flame structure, resulting in unique temperature and gas species fields, which consequently 


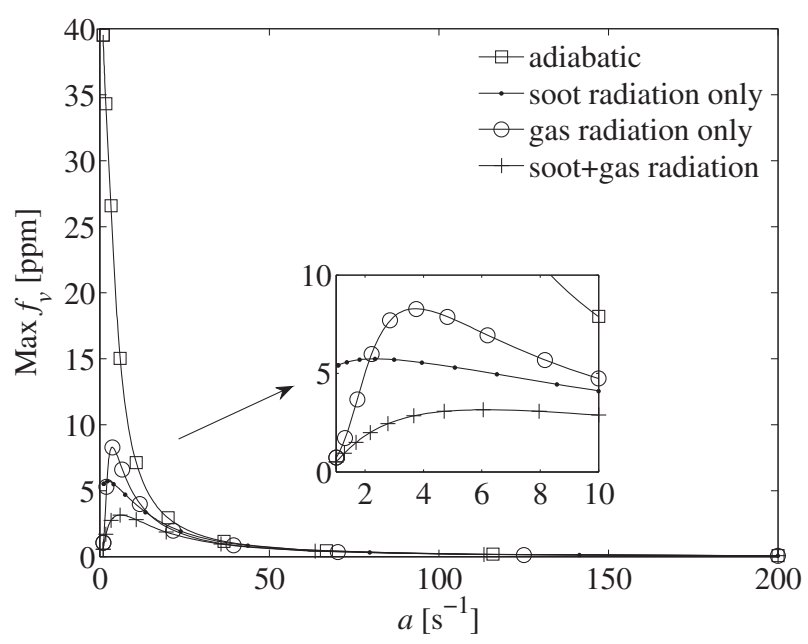

Figure 5. Comparison of maximum $f_{v}$ for different radiative heat losses as a function of the strain rate $a$.

produces a unique soot distribution. If no radiation is accounted for, the model predicts huge amounts of soot that are not realistic, as will be seen in the next section.

In general, the importance of the radiation heat loss on soot predictions shown here agrees with others works in the literature. For example, in the work of Kennedy et al. [28] the comparison between adiabatic and non-adiabatic solutions showed that the concentration drop of $\mathrm{OH}$ and other gas species was due to temperature decrease (due to soot radiation) and mass coupling terms. The same conclusion is reached with the present results. Di Domenico et al. [27] found small differences in $\mathrm{C}_{2} \mathrm{H}_{2}$ and $\mathrm{C}_{6} \mathrm{H}_{6}$ when the soot radiation was accounted for, for the partially premixed ethylene case. For the present ethylene diffusion flame, differences were found for $\mathrm{C}_{2} \mathrm{H}_{2}$ and $\mathrm{C}_{6} \mathrm{H}_{6}$, equal to 2.5 and $5 \%$, respectively, for similar soot amounts. Wang et al. [10] studied ethylene counterflow with the oxidiser stream composed of $25 \% \mathrm{O}_{2}$ and $75 \% \mathrm{~N}_{2}$ by volume and a fuel stream of pure ethylene. In a comparison between a gas-phase model and a model with soot (mass and radiation coupling terms) they found that the coronene (pyrene) concentration was reduced by $30.5 \%$ $(10 \%)$. For the same level of soot, $f_{v, \max }=0.6 \mathrm{ppm}$, but with dry air as oxidiser, the present results showed that the pyrene concentration was reduced by $10.8 \%$ (the employed mechanism does not have coronene).

\subsection{Coupling through mass terms and thermodynamic properties}

In this section additional coupling effects including mass and thermodynamic properties, presented in Section 2.3, are investigated. The effects of strain rate, oxygen content of the oxidiser stream, and pressure are also evaluated.

\section{Strain rate effect}

In order to determine whether full coupling is important, the error between coupled and non-coupled models is analysed. It was found that this error becomes noticeable mostly 


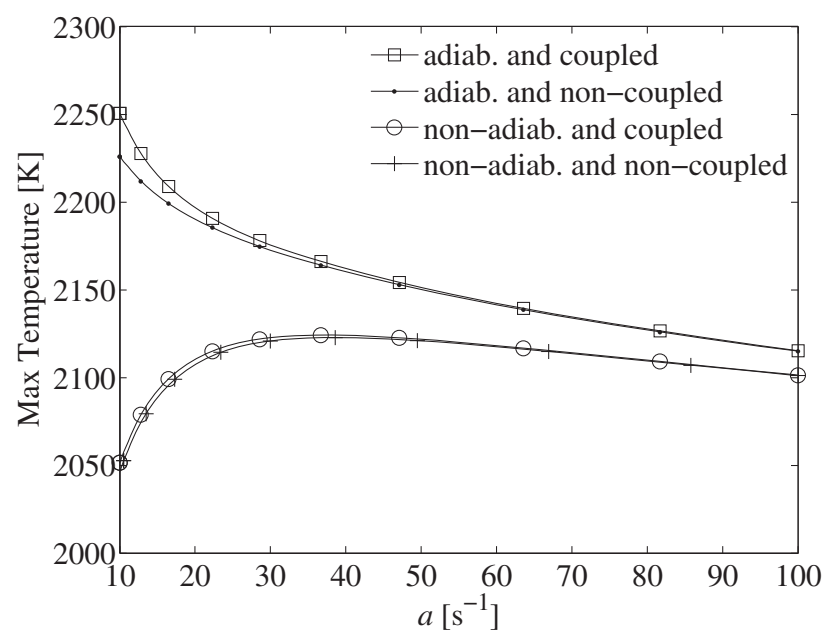

Figure 6. Maximum temperature as a function of the strain rate $a$.



Figure 7. Maximum $f_{v}$ as a function of the strain rate $a$.

in the range $10<a<100 \mathrm{~s}^{-1}$. Therefore, this range is used for discussing the following results.

As shown in Figure 6, within the range of strain rate values explored in this section, only small differences in temperature predictions are found when the coupling terms are not included in the model. The largest absolute temperature difference is only $24 \mathrm{~K}$ for the adiabatic condition while for the non-adiabatic condition it is $5 \mathrm{~K}$. In terms of relative difference (with the coupled case as the reference and values presented in modulus) it is 1.09 and $0.25 \%$ for the adiabatic and non-adiabatic conditions, respectively. The effect of radiative heat losses, on the other hand, is very important and this effect is larger for the lower strain rates with the difference reaching approximately $200 \mathrm{~K}$ at $a=10 \mathrm{~s}^{-1}$.

The maximum $f_{v}$ as a function of strain rate is shown in Figure 7. As the residence time is increased (lower $a$ ) more soot is produced, reaching maximum values of $f_{v}$ equal 




Figure 8. Maximum $Y_{S}$ as a function of the strain rate $a$.

to 7.89 and $2.88 \mathrm{ppm}$ for the adiabatic and non-adiabatic conditions, respectively, at $a=$ $10 \mathrm{~s}^{-1}$. The coupling effect becomes more significant for lower $a$ values due to the higher amounts of soot formed. To evaluate the mass and energy coupling between both phases, only the relative difference between the non-coupled and coupled cases is discussed. For the adiabatic condition, the relative difference for the maximum $f_{v}$ steadily increases from $0.1 \%$ for the highest $a$ value to $14.3 \%$ for the lowest $a$ value. One can define a threshold for errors larger than $1 \%(5 \%)$, which is found at $a=60.5 \mathrm{~s}^{-1}\left(23.3 \mathrm{~s}^{-1}\right)$, corresponding to a maximum $f_{v}$ of $0.51 \mathrm{ppm}(2.34 \mathrm{ppm})$. For the non-adiabatic condition, the relative difference increases from $0.1 \%$ for the highest $a$ to $8.2 \%$ for the lowest $a$ value. Relative differences larger than $1 \%(5 \%)$ are found for $0.51 \mathrm{ppm}(1.9 \mathrm{ppm})$. Figures 6 and 7 show again that the flame radiation is very important for soot modelling if low strain rates are achieved. For the present study, the adiabatic condition overpredicted $f_{v}$ by a factor of approximately three.

In Figure 8 the soot prediction, in terms of mass fraction, is extended to lower strain rates to show some limitations of different modelling approaches. As the residence time increases, the soot mass presents a steep increase for the adiabatic case, reaching unphysical values for the non-coupled case, which is a severe limitation of this case. When the mass coupling is correctly accounted for, the results are more consistent even for the high soot loads achieved in adiabatic calculations. For the non-adiabatic solution, soot formation is limited by the resulting lower temperatures. For large residence times, $Y_{S}$ even decreases due to the intense radiative heat losses ( $T$ decreases) and both coupled and non-coupled models present similar results. However, for large residence times, tending to equilibrium, the employed soot model is not valid since reverse reactions are neglected. A critical point if one decides not to take into account the mass coupling is that the total mass conservation will not be satisfied and the resulting error is equal to the mass of soot formed. For example, for $a=10 \mathrm{~s}^{-1}, Y_{S}$ is 0.051 for the adiabatic condition and 0.016 for non-adiabatic condition, i.e. errors of 5.1 and $1.6 \%$, respectively, in the local mass conservation.

The impact of the coupling terms on the gas-phase species is also investigated. Only the species responsible for soot nucleation $\left(R_{1}\right)$ and surface growth $\left(R_{2}\right), \mathrm{C}_{2} \mathrm{H}_{2}$, and the gas-phase product of these reactions, $\mathrm{H}_{2}$, are presented in detail. 
Figure 9 presents the maximum $\mathrm{C}_{2} \mathrm{H}_{2}$ mass fraction. The relative difference varies from small values at the highest $a, 0.2 \%$ for both adiabatic and non-adiabatic conditions, to significant values for the lowest $a, 6.7 \%$ for adiabatic and $4.2 \%$ for non-adiabatic conditions, with the non-coupled cases always presenting higher amounts of $\mathrm{C}_{2} \mathrm{H}_{2}$. These results are expected, since $\mathrm{C}_{2} \mathrm{H}_{2}$ is not consumed in reactions $R_{1}$ and $R_{2}$ for the non-coupled cases. The behaviour of $\mathrm{C}_{2} \mathrm{H}_{2}$, the soot precursor species in the present model, is defined by a balance between the gas-phase reactions forming and consuming acetylene and, for the coupled cases, the consumption by soot nucleation and surface growth. This balance depends on temperature and residence time. For strain rates larger then $170 \mathrm{~s}^{-1}$ (not shown in the figure), the acetylene mass fraction is reduced until the flame reaches the extinction limit. The behaviour for large strain rates is controlled by the small residence times of these flames. For small strain rates, the acetylene mass fraction is also reduced for all cases, even for the adiabatic and non-coupled case for which the $\mathrm{C}_{2} \mathrm{H}_{2}$ starts to decrease at a strain rate equal to $7.4 \mathrm{~s}^{-1}$ (not shown in the figure). In this circumstance, tending to adiabatic equilibrium, the $\mathrm{C}_{2} \mathrm{H}_{2}$ is more consumed than formed as the strain rate is decreased. For non-adiabatic flames, the radiative heat losses become increasingly important for small strain rates, reducing the flame temperature, which also affects the $\mathrm{C}_{2} \mathrm{H}_{2}$ formation. For the intermediary strain rates shown in Figure 9, temperature and residence time effects are important for all cases, while soot nucleation and surface growth are also important for the coupled cases.

In terms of maximum $\mathrm{H}_{2}$ mass fraction, shown in Figure 10, the relative difference varies from small values for the highest $a, 0.7 \%$ for both adiabatic and non-adiabatic conditions, to large values for the lowest $a, 21.6 \%$ for adiabatic and $9.6 \%$ for non-adiabatic conditions. A consequence of this result is that, since $\mathrm{H}_{2}$ diffuses faster than the other species, the coupling may imply an increase of preferential diffusion effects.

A summary of the above results is presented in Table 2, which shows the critical soot volume fraction, and the corresponding critical soot mass fraction, above which a certain level of error is reached ( 1 and 5\%) for some variables when the mass/thermodynamic property coupling effect is not taken into account, for the non-adiabatic condition only. The

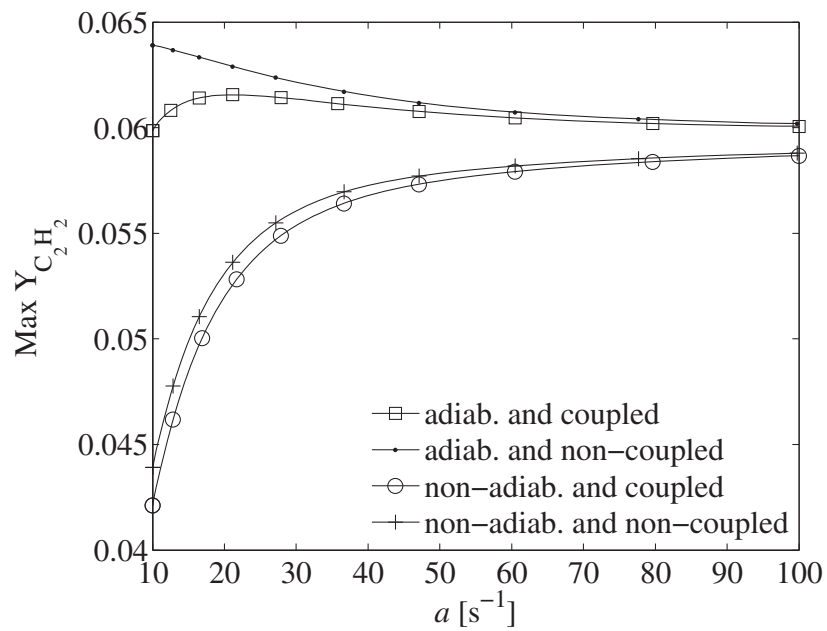

Figure 9. Maximum $\mathrm{C}_{2} \mathrm{H}_{2}$ mass fraction as a function of the strain rate $a$. 


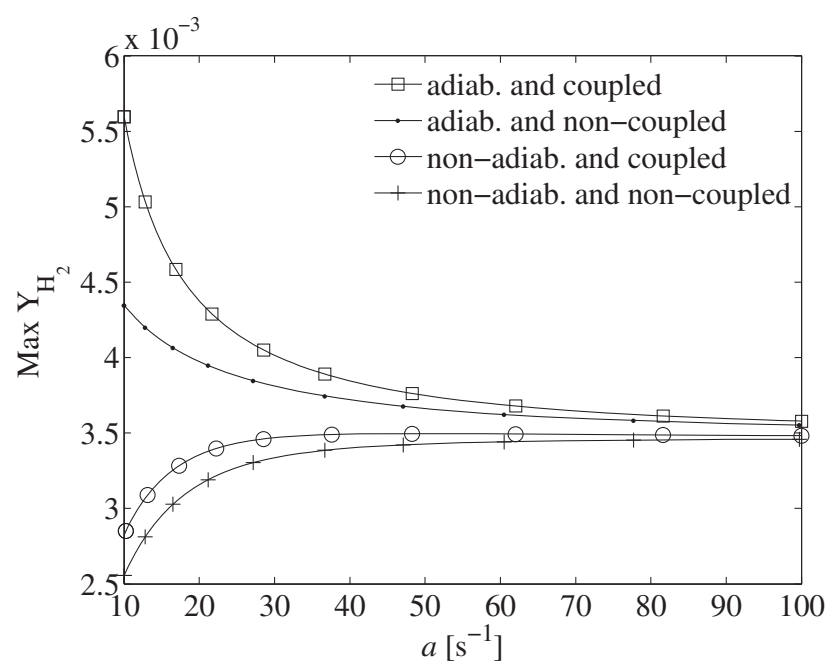

Figure 10. Maximum $\mathrm{H}_{2}$ mass fraction as a function of the strain rate $a$.

outcome of changing the oxidant composition and system pressure are also reported in the table and will be discussed later.

The results for the strain rate effect, presented in Table 2, show that, within the explored limits of soot, the error between coupled and non-coupled did not reach $1 \%$ for the predictions of flame temperature, $N_{S}, \mathrm{O}, \mathrm{CO}$, and $Y_{\mathrm{C}_{6} \mathrm{H}_{6}}$. Nevertheless, the coupling changes the prediction of $f_{v}, Y_{S}$, and other gas species. The most sensitive gas species identified was $\mathrm{H}_{2}$, with the lower threshold of $1 \%$ found in $f_{v \text {, crit }}=0.31 \mathrm{ppm}\left(Y_{S \text {, crit }}=0.0017\right)$. The non-coupled model could not represent the correct soot mass fraction with an error lower than $1 \%$. However, when the higher threshold of $5 \%$ is analysed, the discrepancy of most of the variables does not reach that limit, except for $f_{v}, \mathrm{H}_{2}$, and $\mathrm{H}_{2} \mathrm{O}$, with $\mathrm{H}_{2}$ being the most sensitive with the lower threshold found in $f_{v \text {, crit }}=1.64 \mathrm{ppm}\left(Y_{S \text {, crit }}=0.0089\right)$.

\section{Oxygen and pressure effect}

Even for small residence times (high $a$ ) the soot production may be large if the oxygen content of the oxidant stream is increased due to the higher temperatures found in such flames. Thus, a new set of simulations is carried out for $a=80 \mathrm{~s}^{-1}$ with the oxygen content in the oxidant stream varying from 21 to $45 \%$ on a volume basis. This range of oxygen content was choose in order to achieve amounts of soot comparable with those found in the strain rate effect study $\left(0.0016<Y_{S \text {, } \max }<0.016\right)$. The main results are presented in Table 2. As for the strain the rate effect, the interaction between both phases does not alter the predictions of flame temperature, $N_{S}, \mathrm{H}, \mathrm{O}, \mathrm{OH}, \mathrm{CO}$, and $\mathrm{CO}_{2}$. For all gas species, the discrepancies for not coupling the mass and thermodynamic properties between the two phases are below 5\%, except for soot mass and volume fraction. Here again, $\mathrm{H}_{2}$ is the most sensitive gas species, with the lower threshold of $1 \%$ found in $f_{v}$, crit $=0.32 \mathrm{ppm}\left(Y_{S \text {, crit }}=\right.$ $0.0018)$. The error for maximum $Y_{S}$ non-coupled predictions is also larger than $1 \%$. $f_{v}$ was the first parameter to deviate more than $5 \%\left(Y_{S \text {, crit }}=0.0079\right)$ from the coupled case. Note that changing the oxidant composition resulted in a change in the threshold limits, leading to the conclusion that the importance of the coupling effect is composition dependent. 


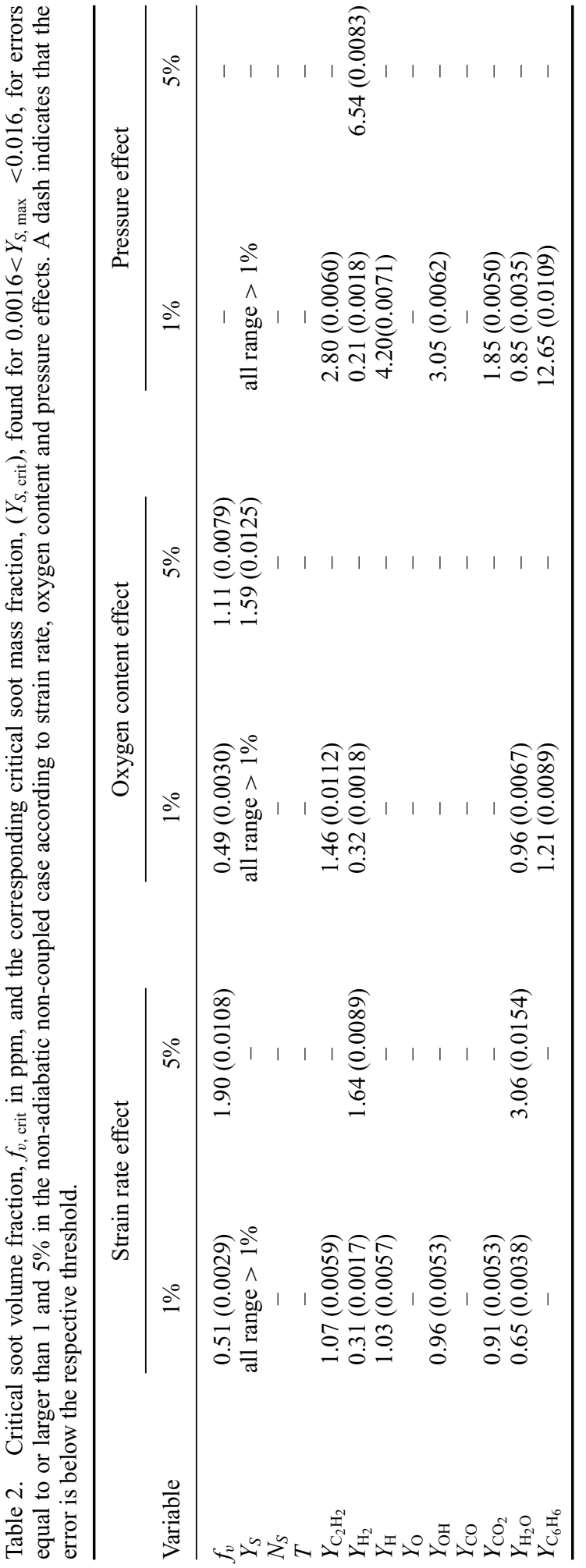


The pressure effect was also investigated and the same method was applied for finding the limit values for pressure. Thus a new set of simulations was carried out for $a=$ $60 \mathrm{~s}^{-1}$, where the pressure was varied from 0.5 to $30 \mathrm{~atm}$. With the increase of pressure the maximum temperature and therefore the soot being formed increased. Results for the pressure effect are to some extend similar to those obtained for the strain rate effect when compared on a mass basis ( $\left.Y_{S \text {, crit }}\right)$. Comparisons for $f_{v}$ were affected by variations in density (see Equation 17). Thus, in this case, it is preferable to use $Y_{S}$ for evaluating the coupling effect. Note that $f_{v}$ does not reach errors greater than $1 \%$, and that now benzene is affected by the soot mass coupling. As in the strain rate effect, the lowest threshold for coupling the

soot terms are based on the $\mathrm{H}_{2}$ species, with values of $Y_{S \text {, crit }}$ equal to $0.0018(0.0083)$ for errors larger than $1 \%(5 \%)$.

From the results presented above it is possible to see that there is a certain coherence among $Y_{S \text {, crit }}$ for the explored effects. Thus, within the limits of the present study, one can propose that $Y_{S}$ close to 0.002 could be a reference value for the choice of the full coupling model. For $Y_{S} \geq 0.002$, local errors larger than $1 \%$ will be present if the mass coupling is not taken into account. For a 5\% threshold a similar reference would be $Y_{S} \geq 0.008$. However, these reference values are not universal, but depend on the fuel type, oxidant composition, and, possibly, multi-dimensional effects.

\subsection{Transport properties effect}

A common approach to reduce the time required to evaluate multicomponent transport properties in flames is to calculate the diffusion coefficients for the gas species assuming unitary Lewis number $\left(\mathrm{Le}_{i}=\lambda / \rho c_{p} D_{i}^{M}=1\right)$. Additionally, simplified formulations are frequently used for other properties. In this section, those proposed in [51] are employed: $\lambda / c_{p}=2.58 \times 10^{-5}(T / 298)^{0.69}\left(\right.$ in $\left.\mathrm{W} \cdot \mathrm{m}^{-1} \mathrm{~K}^{-1}\right)$ and $\mu / c_{p}=1.67 \times 10^{-8}(T / 298)^{0.51}$ (in $\mathrm{kg} \cdot \mathrm{m}^{-1} \mathrm{~s}^{-1}$ ). The effects of such simplifications are evaluated and compared with the coupling effects. The strain rate was varied (from 10 to $100 \mathrm{~s}^{-1}$ ), at atmospheric conditions, and the maximum values for some variables were analysed.

With these simplifications, the flame and the soot coupling effect presented a qualitatively similar behaviour when compared with the simulation using the more detailed approach. The $\mathrm{H}_{2}$ still is the most sensitive gas species with $Y_{S \text {, crit }}=0.0013(0.0067)$ for $1 \%(5 \%)$ of relative error. However the prediction of soot formation is lower for the simplified model. A comparison with the detailed transport model is shown in Figure 11, for the coupled cases only. Notice that at the lowest strain rate the soot formation is reduced by $1.85 \mathrm{ppm}(23.5 \%)$ in the adiabatic condition and by $0.18 \mathrm{ppm}(6.5 \%)$ in the non-adiabatic condition, when the simplified approach is employed.

For maximum temperature profiles the relative difference due to coupling effects also did not reach $1 \%$ for both heat loss conditions. Nevertheless, the temperature of the flames significantly increased for all cases when using the simplified transport approach when compared with the detailed transport model, as can be seen in Figure 12. Notice that at the highest $a$ the temperature is increased by $90 \mathrm{~K}(4.3 \%)$ for both heat loss conditions, while at the lowest $a$ the temperature is increased by $28 \mathrm{~K}(1.2 \%)$ for the adiabatic condition and by $76 \mathrm{~K}(3.7 \%)$ for the non-adiabatic condition.

The comparison between the simplified and the detailed transport models showed that discrepancies in the predictions of temperature, gas species, and soot were larger than those found by not taking the mass and thermodynamic properties coupling effects into account. Thus, the choice of the transport model has a more important impact on soot predictions than full coupling between the phases. 


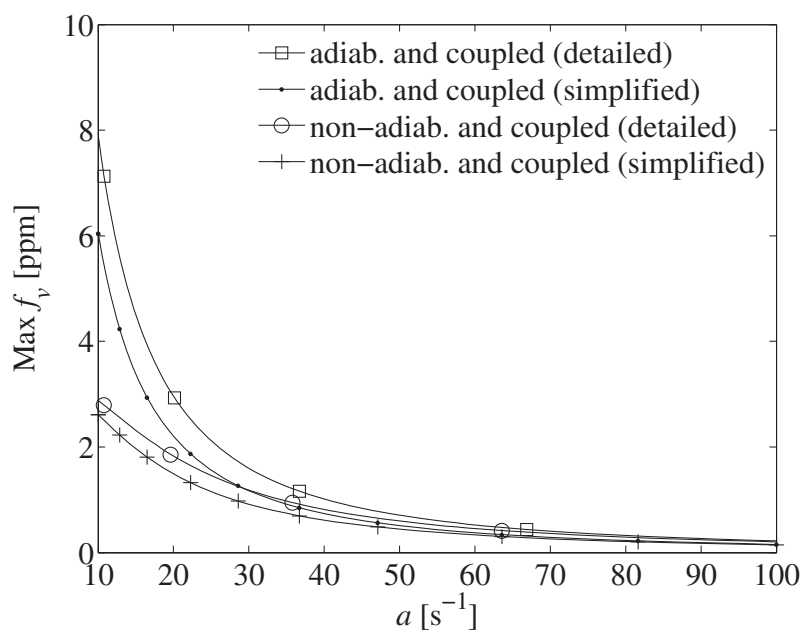

Figure 11. Comparison of maximum $f_{v}$ for different transport properties approaches as a function of the strain rate $a$.

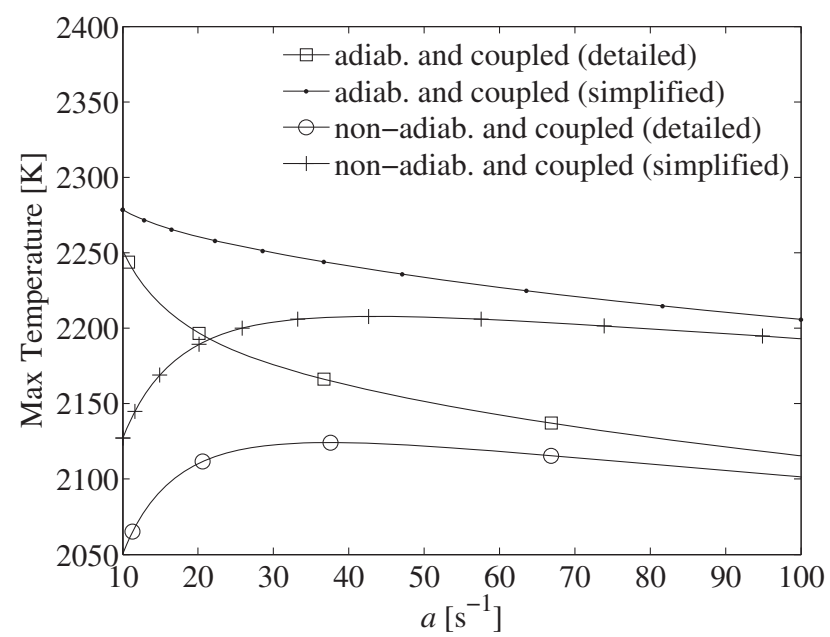

Figure 12. Comparison of maximum temperature for different transport properties approaches as a function of the strain rate $a$.

\section{Conclusions}

In this work, a numerical model is developed aiming at investigating soot formation in different conditions for an ethylene counterflow diffusion flame. In order to assess modelling limitations, the mass and energy coupling between solid soot particles and gas-phase species are investigated and quantified. A semi-empirical two-equation model is chosen for predicting soot mass fraction and number density. The model describes particle nucleation, surface growth, and oxidation. For the gas phase, a detailed kinetic mechanism is considered. Additionally, the effect of considering gas and soot radiation heat losses is evaluated in the optically thin limit approximation. 
Simulations were done for a range of conditions that produce low-to-significant amounts of soot. To achieve these conditions three strategies were adopted. First, at atmospheric pressure, the strain rate was varied from low-to-high values, with the lower values resulting in larger residence times and, consequently, in higher soot formation. Second, for a particular strain rate and atmospheric pressure, the oxygen content in the oxidiser stream was increased, which leads to higher flame temperatures and, consequently, higher soot production. Third, for a specific strain rate, the pressure was increased, also resulting in higher soot production. Additionally, the effect of a simplified transport properties model was analysed.

It was found that the gas and soot radiation terms are of primary importance for flame simulations. The importance of the radiation heat loss on soot predictions shown here is consistent with the literature, even though some works are in different configurations. The additional coupling terms (mass and thermodynamic properties) are generally a secondorder effect, but their importance increases as the soot amount increases.

As a general recommendation, full coupling should be taken into account only when the soot mass fraction, $Y_{S}$, is equal to or larger than 0.008 . However, if a higher precision is required, with errors lower than $1 \%$, full coupling should be taken into account when $Y_{S} \geq 0.002$, which is the lower threshold of the most sensitive gas species, $\mathrm{H}_{2}$. The non-coupled model could not represent the soot mass fraction predicted by the coupled model with errors lower than $1 \%$. For lower soot amounts, coupling through soot mass and thermodynamic properties may be neglected as a first approximation, remembering that an error in local mass conservation will be present.

The results also showed that discrepancies from choosing different transport models (detailed or simplified) are larger than those found from not fully coupling the phases.

\section{Disclosure statement}

No potential conflict of interest was reported by the authors.

\section{Funding}

The first author acknowledges the financial support of the Coordenação de Aperfeiçoamento de Pessoal de Nível Superior (CAPES) [Project No. BEX5381-13-4].

\section{ORCID}

Jeroen Adrianus van Oijen (1) http://orcid.org/0000-0002-4283-2898

Laurentius Philippus Hendrika de Goey [ㄱ http://orcid.org/0000-0001-6625-3113

\section{References}

[1] I.M. Kennedy, Models of soot formation and oxidation, Prog. Energ. Combust. 23 (1997), pp. 95-132.

[2] K. Leung, R. Lindstedt, and W. Jones, A simplified reaction mechanism for soot formation in nonpremixed flames, Combust. Flame 87 (1991), pp. 289-305.

[3] M. Fairweather, W. Jones, and R. Lindstedt, Predictions of radiative transfer from a turbulent reacting jet in a cross-wind, Combust. Flame 89 (1992), pp. 45-63.

[4] T. Kim and Y. Kim, Interactive transient flamelet modeling for soot formation and oxidation processes in laminar non-premixed jet flames, Combust. Flame 162 (2015), pp. 1660-1678.

[5] A. Violi, Modeling of soot particle inception in aromatic and aliphatic premixed flames, Combust. Flame 139 (2004), pp. 279-287.

[6] A. D'Anna and J. Kent, Modeling of particulate carbon and species formation in coflowing diffusion flames of ethylene, Combust. Flame 144 (2006), pp. 249-260. 
[7] J. Appel, H. Bockhorn, and M. Frenklach, Kinetic modeling of soot formation with detailed chemistry and physics: Laminar premixed flames of C2 hydrocarbons, Combust. Flame 121 (2000), pp. 122-136.

[8] M. Skjøth-Rasmussen, P. Glarborg, M. Østberg, J. Johannessen, H. Livbjerg, A. Jensen, and T. Christensen, Formation of polycyclic aromatic hydrocarbons and soot in fuel-rich oxidation of methane in a laminar flow reactor, Combust. Flame 136 (2004), pp. 91-128.

[9] V. Chernov, M.J. Thomson, S.B. Dworkin, N.A. Slavinskaya, and U. Riedel, Soot formation with $\mathrm{Cl}$ and $\mathrm{C} 2$ fuels using an improved chemical mechanism for PAH growth, Combust. Flame 161 (2014), pp. 592-601.

[10] Y. Wang, A. Raj, and S.H. Chung, Soot modeling of counterflow diffusion flames of ethylenebased binary mixture fuels, Combust. Flame 162 (2015), pp. 586-596.

[11] C.J. Pope and J.B. Howard, Simultaneous particle and molecule modeling (SPAMM): An approach for combining sectional aerosol equations and elementary gas-phase reactions, Aerosol Sci. Technol. 27 (1997), pp. 73-94. Available at http://dx.doi.org/10.1080/ 02786829708965459.

[12] Q. Zhang, H. Guo, F. Liu, G. Smallwood, and M. Thomson, Modeling of soot aggregate formation and size distribution in a laminar ethylene/air coflow diffusion flame with detailed PAH chemistry and an advanced sectional aerosol dynamics model, Proc. Combust. Inst. 32 (2009), pp. 761-768.

[13] H. Pitsch, E. Riesmeier, and N. Peters, Unsteady flamelet modeling of soot formation in turbulent diffusion flames, Combust. Sci. Technol. 158 (2000), pp. 389-406.

[14] M. Frenklach, Method of moments with interpolative closure, Chem. Engng Sci. 57 (2002), pp. 2229-2239.

[15] M. Balthasar and M. Frenklach, Monte-Carlo simulation of soot particle coagulation and aggregation: The effect of a realistic size distribution, Proc. Combust. Inst. 30 (2005), pp. $1467-1475$.

[16] D. Chen, Z. Zainuddin, E. Yapp, J. Akroyd, S. Mosbach, and M. Kraft, A fully coupled simulation of PAH and soot growth with a population balance model, Proc. Combust. Inst. 34 (2013), pp. $1827-1835$.

[17] A. Raj, M. Celnik, R. Shirley, M. Sander, R. Patterson, R. West, and M. Kraft, A statistical approach to develop a detailed soot growth model using PAH characteristics, Combust. Flame 156 (2009), pp. 896-913.

[18] R.J. Hall, Radiative dissipation in planar gas-soot mixtures, J. Quant. Spectrosc. \& Rad. Trans. 51 (1994), pp. 635-644. Available at http://dx.doi.org/10.1016/0022-4073(94)90117-1.

[19] F. Liu, H. Guo, G.J. Smallwood, and O.L. Gulder, Effects of gas and soot radiation on soot formation in a coflow laminar ethylene diffusion flame, J. Quant. Spectrosc. \& Rad. Trans. 73 (2002), pp. 409-421.

[20] Y. Sivathanu and J. Gore, Coupled radiation and soot kinetics calculations in laminar acetylene/air diffusion flames, Combust. Flame 97 (1994), pp. 161-172.

[21] F. Liu, H. Guo, G.J. Smallwood, and M.E. Hafi, Effects of gas and soot radiation on soot formation in counterflow ethylene diffusion flames, J. Quant. Spectrosc. \& Rad. Trans. 84 (2004), pp. 501-511.

[22] J. Moss, C. Stewart, and K. Young, Modeling soot formation and burnout in a high temperature laminar diffusion flame burning under oxygen-enriched conditions, Combust. Flame 101 (1995), pp. 491-500.

[23] B.A.V. Bennett, C.S. McEnally, L.D. Pfefferle, M.D. Smooke, and M.B. Colket, Computational and experimental study of the effects of adding dimethyl ether and ethanol to nonpremixed ethylene/air flames, Combust. Flame 156 (2009), pp. 1289-1302.

[24] M.R. Charest, Ö.L. Gülder, and C.P. Groth, Numerical and experimental study of soot formation in laminar diffusion flames burning simulated biogas fuels at elevated pressures, Combust. Flame 161 (2014), pp. 2678-2691.

[25] M.R. Charest, C.P. Groth, and Ö.L. Gülder, A computational framework for predicting laminar reactive flows with soot formation, Combust. Theory Model. 14 (2010), pp. 793-825.

[26] R. Mehta, D. Haworth, and M. Modest, An assessment of gas-phase reaction mechanisms and soot models for laminar atmospheric-pressure ethylene-air flames, Proc. Combust. Inst. 32 (2009), pp. 1327-1334.

[27] M. Di Domenico, P. Gerlinger, and M. Aigner, Development and validation of a new soot formation model for gas turbine combustor simulations, Combust. Flame 157 (2010), pp. 246-258. Available at http://dx.doi.org/10.1016/j.combustflame.2009.10.015. 
[28] I.M. Kennedy, C. Yam, D.C. Rapp, and R.J. Santoro, Modeling and measurements of soot and species in a laminar diffusion flame, Combust. Flame 107 (1996), pp. 368-382.

[29] D. Carbonell, A. Oliva, and C. Perez-Segarra, Implementation of two-equation soot flamelet models for laminar diffusion flames, Combust. Flame 156 (2009), pp. 621-632.

[30] L.P.H. de Goey and J.H.M. ten Thije Boonkkamp, A flamelet description of premixed laminar flames and the relation with flame stretch, Combust. Flame 119 (1999), pp. 253-271. Available at http://dx.doi.org/10.1016/S0010-2180(99)00052-8.

[31] Q. Zhang, H. Guo, F. Liu, G.J. Smallwood, and M.J. Thomson, Implementation of an advanced fixed sectional aerosol dynamics model with soot aggregate formation in a laminar methane/air coflow diffusion flame, Combust. Theory Model. 12 (2008), pp. 621-641.

[32] I.M. Kennedy, W. Kollmann, and J.Y. Chen, A model for soot formation in a laminar diffusion flame, Combust. Flame 81 (1990), pp. 73-85.

[33] O. Ezekoye and Z. Zhang, Soot oxidation and agglomeration modeling in a microgravity diffusion flame, Combust. Flame 110 (1997), pp. 127-139.

[34] J. Nagle and R. Strickland-Constable, Oxidation of carbon between 1000-2000 C, in Proceedings of the Fifth Conference on Carbon, University Park, PA, Vol. 1, Macmillan, New York, 1962, pp. 154-164. Available at http://dx.doi.org/10.1016/B978-0-08-009707-7.50026-1.

[35] D. Bradley, G. Dixon-Lewis, S.E. din Habik, and E. Mushi, The oxidation of graphite powder in flame reaction zones, Symp. (Int.) Combust. 20 (1984), pp. 931-940.

[36] N. Eaves, S. Dworkin, and M. Thomson, The importance of reversibility in modeling soot nucleation and condensation processes, Proc. Combust. Inst. 35 (2015), pp. 1787-1794.

[37] R. Barlow, A. Karpetis, J. Frank, and J.Y. Chen, Scalar profiles and NO formation in laminar opposed-flow partially premixed methane/air flames, Combust. Flame 127 (2001), pp. 21022118.

[38] M. Smooke, C. McEnally, L. Pfefferle, R. Hall, and M. Colket, Computational and experimental study of soot formation in a coflow, laminar diffusion flame, Combust. Flame 117 (1999), pp. $117-139$.

[39] J. Chen, Y. Liu, and B. Rogg, $\mathrm{CO}-\mathrm{H}_{2}-\mathrm{N}_{2}$ /air diffusion flames: Thermal radiation and transient effects, in Reduced Kinetic Mechanisms for Applications in Combustion Systems, N. Peters and B. Rogg, eds., Vol. 15, Springer, 1993, pp. 196-223.

[40] International Workshop on Measurement and Computation of Turbulent Nonpremixed Flames (TNF), R.S. Barlow, ed., Sandia National Laboratories. Available at $\mathrm{http}: / / \mathrm{http}: / /$ www.sandia.gov/TNF/radiation.html.

[41] M.W. Chase Jr, NIST-JANAF thermochemical tables, in Journal of Physical and Chemical Reference Data, 4th edn., 1998.

[42] C. Crowe, editor. Multiphase Flow Handbook. Mechanical Engineering Series [Internet], CRC Press, 2005 Sep 19; Available at http://dx.doi.org/10.1201/9781420040470.

[43] CHEM1D, One-dimensional laminar flame code, Eindhoven University of Technology. Available at http://www.combustion.tue.nl.

[44] G. Blanquart, P. Pepiot-Desjardins, and H. Pitsch, Chemical mechanism for high temperature combustion of engine relevant fuels with emphasis on soot precursors, Combust. Flame 156 (2009), pp. 588-607.

[45] C. Wilke, A viscosity equation for gas mixtures, J. Chem. Phys. 18 (1950), pp. 517-519.

[46] S. Mathur, P. Tondon, and S. Saxena, Thermal conductivity of binary, ternary and quaternary mixtures of rare gases, Mol. Phys. 12 (1967), pp. 569-579.

[47] J. Hwang and S. Chung, Growth of soot particles in counterflow diffusion flames of ethylene, Combust. Flame 125 (2001), pp. 752-762.

[48] U. Vandsburger, I. Kennedy, and I. Glassman, Sooting counterflow diffusion flames with varying oxygen index, Combust. Sci. Technol. 39 (1984), pp. 263-285.

[49] G. Smith, D.G.M. Frenklach, N. Moriarty, B. Eiteneer, M. Goldenberg, C. Bowman, R. Hanson, S. Song, W. Gardiner, V. Lissianski, and Z. Qin, Gri-mech 3.0 (2000). Available at http://www.me.berkeley.edu/gri_mech/.

[50] M. Smooke, I. Puri, and K. Seshadri, A comparison between numerical calculations and experimental measurements of the structure of a counterflow diffusion flame burning diluted methane in diluted air, Symp. (Int.) Combust. 21 (1988), pp. 1783-1792.

[51] M. Smooke and V. Giovangigli, Formulation of the premixed and nonpremixed test problems, in Reduced Kinetic Mechanisms and Asymptotic Approximations for Methane-Air Flames, Vol. 384 of the series Lecture Notes in Physics, Springer-Verlag, Berlin, 1991, pp. 1-28. Available at http://dx.doi.org/10.1007/BFb0035363. 